\title{
Design of a test rig for cleaning studies and evaluation of laboratory-scale experiments using pink guava puree as a fouling deposit model
}

\begin{abstract}
A cleaning-in-place (CIP ) test rig is commonly used to investigate the cleanability of food apparatus. The main focus of this work was to design a laboratory-scale cleaning test rig that operates at a fluid velocity of up to $2 \mathrm{~m} / \mathrm{s}(\operatorname{Re}=2.5 \times 105)$ and that is capable of withstanding contact with detergents and disinfectants at temperatures from 20 to $70 \mathrm{C}$. The design followed the standard design of a recirculating water tunnel that includes a test section. Computational fluid dynamic simulation was performed to find the minimum entry length to obtain fully developed flow at the test section. Cleanability of a flat stainless steel plate was investigated using pink guava puree as a physical fouling deposit model. The CIP process only considered the alkaline cleaning stage at cleaning condition of $0-2.0 \mathrm{wt} \% \mathrm{NaOH}, 35-$ $70 \mathrm{C}$ and $0.6-1.5 \mathrm{~m} / \mathrm{s}$. In general, removal of fouling deposit increased with increasing chemical concentration, temperature and velocity. These findings may be used to improve the CIP for real conditions in the food industry.
\end{abstract}

